\title{
Symmetry of echinoderms: From initial bilaterally-asymmetric metamerism to pentaradiality
}

\author{
Sergey V. Rozhnov \\ Borissiak Paleontological Institute RAS, Moscow, Russia; Rozhnov@paleo.ru
}

Received 3 December 2013; revised 3 January 2014; accepted 10 January 2014

Copyright (C) 2014 Sergey V. Rozhnov. This is an open access article distributed under the Creative Commons Attribution License, which permits unrestricted use, distribution, and reproduction in any medium, provided the original work is properly cited. In accordance of the Creative Commons Attribution License all Copyrights (C) 2014 are reserved for SCIRP and the owner of the intellectual property Sergey V. Rozhnov. All Copyright (C) 2014 are guarded by law and by SCIRP as a guardian.

\section{ABSTRACT}

Echinoderm radial symmetry has first appeared in the ambulacral system, when the ambulacral channel assumed the shape of a closed ring or a horseshoe with approximated ends, and then spread onto other organ systems. Its origin was a natural consequence of a steady increase of the original asymmetry of bilaterally-asymmetric three-segmented ancestors of echinoderms, culminated by closing of the ancestral linear metamerism into radiality. The evolutionary transformation from a simple pouchlike hydrocoel with one side channel to an elongated hydrocoel (located under the oesophagus) with two side channels, and finally to a nearly closed horseshoeshaped hydrocoel with three radial channels can be reconstructed based on the theca structure and the number of ambulacra in the row SolutaCincta-Helicoplacoidea. After the hydrocoel with three outbound ambulacral channels circled around the oesophagus as a horseshoe, it either closed into a ring, or its ends became closely approximated. This has determined the primary triradiate symmetry, which quickly transformed into pentaradial symmetry of the 2-1-2 type as a result of branching of two of the three primary radial channels. This occurred no earlier than the Late Vendian, when the first bilaterians appeared to have begun to acquire body appendages, and no later than the Early Cambrian, when the first skeletal remains of echinoderms entered the fossil record (in the Atdabanian). The 2-1-2 pentaradial symmetry evolved into the true pentaradiality as a result of shifting the timing of tentacle branching to earlier stages of ontogenesis and even spreading of the five tentacle primordia over the ambulacral ring. This occurred during the Ordovician.

\section{KEYWORDS}

Echinodermata; Symmetry; Asymmetry; Metamerism; Pentaradiality; Body Plan; Hox Genes; Colinearity

\section{INTRODUCTION}

The area of study dedicated to body plan symmetries and focused on discovery and comparative analysis of key symmetry elements across taxa has been called promorphology [1]. Echinoderms are of special interest in this regard because they display the greatest number of different symmetry types (Figure 1), expressed, moreover, on top of a profound asymmetry [2,3]. In presentday, echinoderm radial (usually pentaradial) symmetry with its multiple symmetry planes and a central rotation axis is combined with bilateral symmetry and metamerism.

Echinoderm coeloms arise during early development as three bilaterally symmetric pairs of primordia, but their subsequent growth is different between the two sides of the body, which reflects the deep asymmetry of echinoderm morphology. In many echinoderms, asymmetry is also expressed in the spiral shape of the gut, usually coiling clockwise in sea lilies (Figure 2), sea urchins, and holothurians. This "internal" asymmetry of modern echinoderms corresponds, to some degree, to the bilateral asymmetry of skeleton in carpozoans-solutes, stylophorans, and cinctans - and spiral arrangement of ambulacra in helicoplacoids. Bilaterally-asymmetric carpozoans, or at least some of them, have been considered as ancestors of pentaradial echinoderms [4-7]. This hypothesis, however, is not fully convincing because the morphology of many such forms, particularly stylophorans, does not easily lend itself to unambiguous interpretation. One exam- 

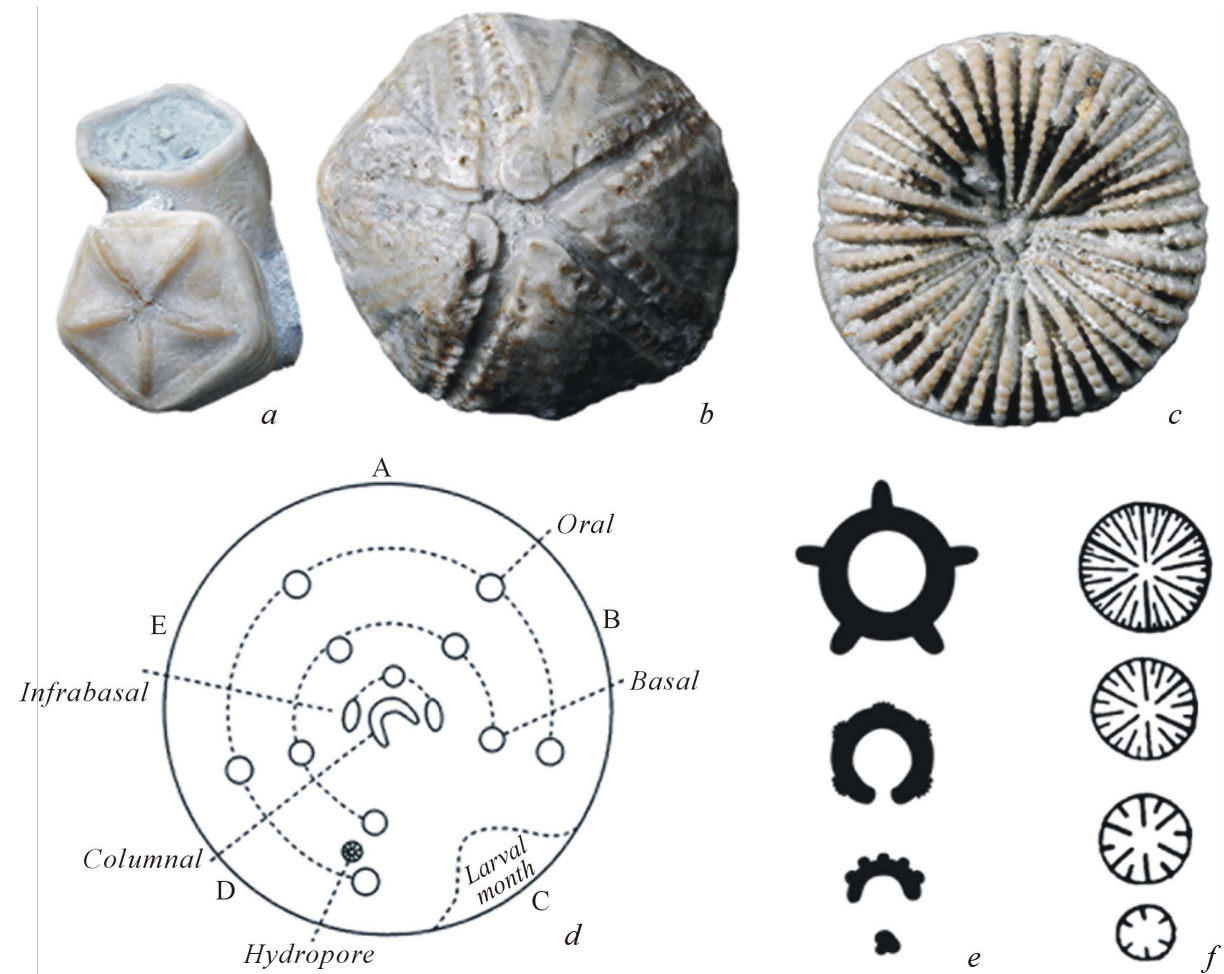

Figure 1. Radial symmetry of echinoderms and corals: (a) the edrioasteroid Cyathocystis (oral view) and (b) the rhombiferan Cystoblastus (oral view), Ordovician of Estonia; (c) the rugose coral Palaeocyclus porpita from above, Silurian of Gotland. (d) the horseshoe-shaped stage in the ambulacral ring ontogenesis of a crinoid, showing arrangement of skeletal elements, diagrammatically [47]; (e) a generalized diagram of the ambulacral ring development; (f) a generalized diagram of the development of septa in hexacorals.

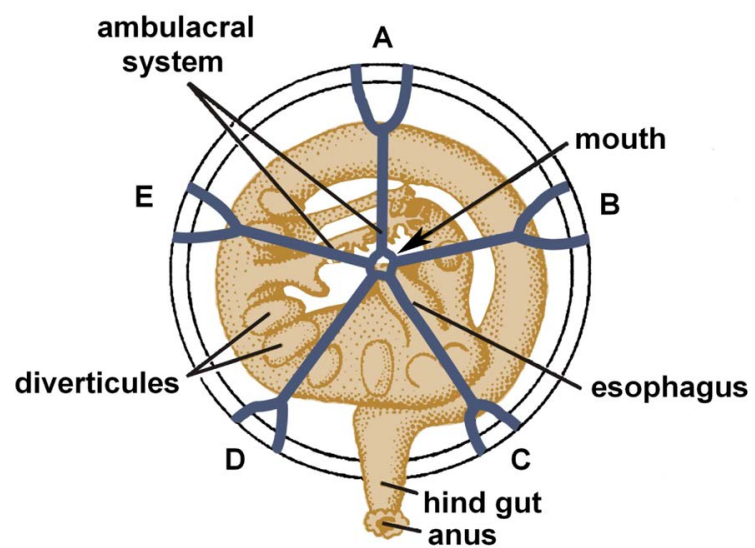

Figure 2. The ambulacral (pentaradial) and digestive (spiral) systems of a crinoid [48].

ple is the long-standing debate between Jefferies with his students and proponents of the aulacophoral interpretation of stylophorans [5,8-12]. Moreover, pentaradial echinoderms enter the geological record somewhat earlier than bilaterally-asymmetric echinoderms.

Together with some morphological considerations, this fact prompted the idea that the bilaterally-asymmetric forms had evolved from the radially symmetric ones via paedomorphosis [13]. This hypothesis does not seem well substantiated, either, because on the geological scale the time difference between the first appearances of the asymmetric and radial forms is small [14] and can be due to incompleteness of the fossil record, while morphological differences between these forms are profound $[15,16]$. Moreover, no intermediate forms documenting the progress of this far-reaching paedomorphic change are known. However, the same facts speak against the idea of carpozoan echinoderms being direct ancestors to pentaradial echinoderms. Therefore, it seems more likely that carpozoans have not been direct ancestors of pentaradial echinoderms, but their structure nevertheless reflects the main stages in the evolution of radial symmetry. My analysis of the origin of echinoderm radiality rests on this assumption $[15,17]$. Whether some of the currently known carpozoans evolved directly from the immediate ancestors of radially symmetric echinoderms or, via paedomorphosis, from the already radially symmetric forms is of no importance for such analysis. In both cases, carpozoans reflect the evolution of echinoderm pentaradiality. Based on this idea, I will attempt to trace out connections between different symmetry types displayed by echinoderms and demonstrate how the evolutionary succession 
of these types was predetermined by the symmetry of the echinoderm ancestors.

\section{PRELIMINARY CONSIDERATIONS}

The same type of symmetry can be observed among unrelated organisms. However, both the evolutionary and ontogenetic origins of similar body plans can be completely different. For example, the radial symmetry of corals arises as their body cavity becomes successively divided into chambers by septa. In contrast, the radial symmetry of echinoderms results from the hydrocoel primordium, together with radial channel primordia, bending around the oesophagus to form a closed ambulacral ring, off which several, usually five, ambulacral channels radiate symmetrically. It is the symmetry of the ambulacral ring that patterns the development of radial symmetry in the rest of the body.

Therefore, reconstruction of the hydrocoel structure in the most ancient echinoderms deserves special attention. The development of symmetry during the ontogenesis of present-day echinoderms can be studied in detail. In contrast, fossil forms are usually represented by skeletons at the latest stages of development. Nevertheless, late ontogenesis of the skeleton and correlated organ systems can be reconstructed, at least partially, based on the age variation observed among the fossils.

Another approach focuses on aberrant forms, which arise via deviation of ontogenesis from its normal course. Such aberrant forms can be recognized as rare variants in the spectrum of individual variation of a particular species or as separate taxa, sometimes of a high rank, as is exemplified by minor classes of echinoderms. These deviations can provide information on some aspects of early ontogenesis, which cannot be directly deduced from normal adult morphology. This is so because many aberrations result from paedomorphosis or other heterochronies, which lead to expression of traits normally expressed in early ontogenesis during the adult stage or reveal latent potencies of future trait evolution. Reconstruction of symmetry ontogenesis in fossil forms, based on the study of age variation or morphogenetic aberrations in comparison with morphogenesis of present-day forms, can open ways to reconstruction of symmetry evolution.

\section{ECHINODERM RADIAL SYMMETRY}

The radial symmetry of echinoderms is usually expressed as pentamery (Figure 1). It patterns not the entire body, but only particular organ systems: ambulacral, nervous, skeletal, and some others. In the skeleton it is primarily determined by the arrangement of ambulacra, i.e. food-gathering grooves or similar structures containing radial ambulacral channels. Such structures can be part of the theca or extend outside as arms or brachioles.
In the first case they determine the symmetry directly and in the second indirectly, through the plates surrounding the mouth (between which run the proximal parts of the ambulacra). In phylogenesis it is sometimes possible to observe a gradual spread of pentaradial symmetry through the entire theca starting from these plates, in the order of their appearance during ontogenesis [18,19].

The role of ambulacra as organizers of pentaradial symmetry has been emphasized by Hotchkiss [20], who suggested the interesting "ray-as-appendages" model of the origin of echinoderm pentaradiality. Nevertheless, the latter is determined first of all by the number of radial ambulacral channels coming off the ambulacral ring. Therefore, to understand its origin in echinoderms we should first clarify the origin of pentaradiality in their ambulacral rings. After its establishment, its gradual spread onto other organ systems, at least the skeleton, can be traced on fossil material.

During ontogenesis the ambulacral ring becomes radially symmetric as a result of its primordium (the left hydrocoel) circling clockwise around what will become pharynx (i.e. the anteroposterior body axis) and closing into a ring (Figures $\mathbf{1}(\mathrm{d})$ and (e)). To describe this process Minsuk et al. [21] have introduced the notion of the circumoral body axis, which becomes segmented into five sectors. In other words, the symmetry of the ambulacral ring primordium can be described as a curved metamerism eventually closing into a radiality [19].

Therefore, echinoderm radiality arises through bending, due to asymmetrical growth, of the initial metamerism until the anterior end of the growing primordium finally reaches and fuses with its own posterior end, so that the hydrocoel pouch becomes a closed ambulacral ring. This genesis of radiality is profoundly different from the mechanism observed in corals, i.e. successive division of the body cavity (Figures 1(c) and (f)). Metameric development of the ambulacral ring includes the appearance of serially arranged ambulacral channel primordia.

In present-day eleutherozoan echinoderms sensu Sumrall \& Sprinkle [22] — echinoids, asteroids, ophiuroids, and holothurians - five ambulacra radiate directly off the mouth. Sumrall \& Wray [13] call this true pentaradial symmetry. In many Paleozoic echinoderms only three ambulacra extend directly off the mouth, two of them bifurcating at some distance away to produce additional two ambulacra (Figure 3). This fundamentally bilateral arrangement of ambulacra is referred to as the 2-1-2 pattern. It is well reflected in the structure of the plates surrounding the mouth, among which three extend and two do not extend all the way to the center. This may indicate that only three radial channels were extending off the ambulacral ring. Besides blastozoan echinoderms and edrioasteroids, the 2-1-2 pattern occurs in crinoids [15,19]. 


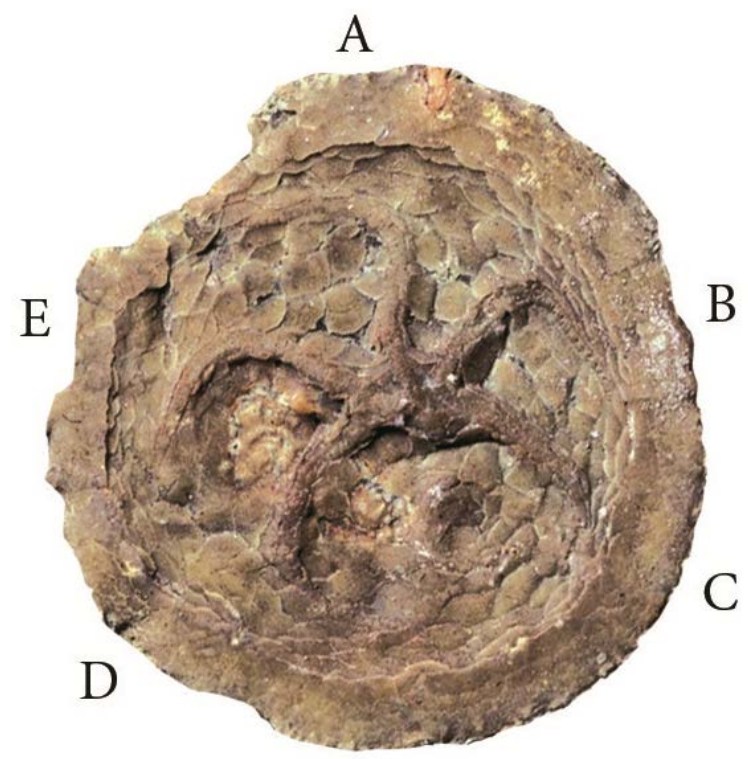

Figure 3. Pentaradial symmetry of the 2-1-2 type in the edrioasteroid Krama, Devonian of the St. Petersburg area.

Yet, in present-day crinoids five channels radiate immediately off the ambulacral ring, just like in eleutherozoans. This suggests that in the crinoid ancestors, or at least in early crinoids, only three ambulacral channel radiated immediately off the ambulacral ring which resulted in the 2-1-2 arrangement of oral plates. Later in evolution the structure had changed to five ambulacra coming directly off the ring, but the plate arrangement remained unchanged.

Sumrall \& Wray [13] have convincingly argued that the reduction of the number of ambulacra in blastozoan echinoderms and crinoids was due to paedomorphosis. Paedomorphic reduction of structures follows, in the reverse order, the sequence of their appearance in ontogenesis. Available data on the ontogenesis of edrioasteroids [23,24], glyptocystitoids [25-27], and gogiids [28] indicate that in the majority of early pentaradial echinoderms the order of ambulacra appearance was similar: first developed the two side ambulacra, corresponding to $\mathrm{B}+\mathrm{C}$ on the right and $\mathrm{D}+\mathrm{E}$ on the left, then the unbranching ambulacrum A, and finally each of the two side ambulacra bifurcated [13].

Therefore, unless due to some unknown reasons the order of ambulacra appearance had changed, the reconstructions by Sumrall \& Wray [13] of the evolution of blastozoans and crinoids with aberrant number of ambulacra may well be accurate. However, we would like to better understand the transition between the 2-1-2 pattern and true pentaradial symmetry. It is possible that it occurred independently and differently during the early evolution of body plans of the main eleutherozoans (echinoids, asteroids, ophiuroids, holothurians, and ophiocistioids) and crinoid lineages. For crinoids a possible mecha- nism of such transition has already been suggested [19] based on the ontogenesis of present-day and the morphology of Paleozoic forms: the timing of appearance of all five ambulacrum primordia shifts onto the early stages of the ambulacral ring development (Figure 4). Correspondingly, bifurcation of ambulacra shifts onto the earliest stages of their ontogenesis. It is possible that in some eleutherozoan lineages this stage was followed by gradual rearrangement of radial channels to become evenly spaced along the circumference of the growing ambulacral ring, resulting in the characteristic true pentaradial symmetry of these clades. In crinoids, however, the process was different: the entire ring primordium with five tentacle primordia (ambulacral channel primordia) underwent metameric, serial fivefold multiplication and then closed into an ambulacral ring with five radial channels within each of its five sectors. This is reflected in ontogenesis of present-day crinoids, in which five tentacle primordia arise within each sector [29].

Later the central tentacle continues growing into a racdial ambulacral channel, while the two pairs of tentacle primordia on each of its sides undergo reduction. In some Paleozoic disparid crinoids all or a significant part of tentacle primordia developed into radial channels, forming multiple arms coming off each radial plate of an adult individual (Figure 4). This mechanism explains the origin of numerous arms in the Devonian Anamesocrinus (five at each radial plate) and Late Paleozoic allagecrinids and catillocrinids with variable number of arms at each radial plate. That this peculiar structure resulted from numerous radial channels coming directly off the ambulacral ring is confirmed by a contrast between these crinoids and Acolocrinus, a genus of uncertain systematic position, in which multiple facets for arm attachment at each radial plate clearly develop as a result of a series of close-set bifurcations of the single ambulacrum connected to that plate (Figures 4(h) and (i)).

Therefore, the structure and relative position of ambulacra allow confident reconstruction of the ambulacral ring and the number and arrangement of radial channels. In the evolution of blastozoans, crinoids, and eleuterozoans an ambulacral ring with three outbound radial channels, two of them bifurcating at some distance away (the 2-1-2 pattern), has transformed into an ambulacral ring with five channels directly connected to it (true pentaradial symmetry). Deviations from pentaradial symmetry in these groups can usually be explained by paedomorphosis and other heterochronies [13,19]. In most cases such deviations do not affect the integrity of the ambulacral ring, which remains closed, as evidenced by the oral plates retaining their pentaradial arrangement and by the presence of variation in the number of ambulacra. 


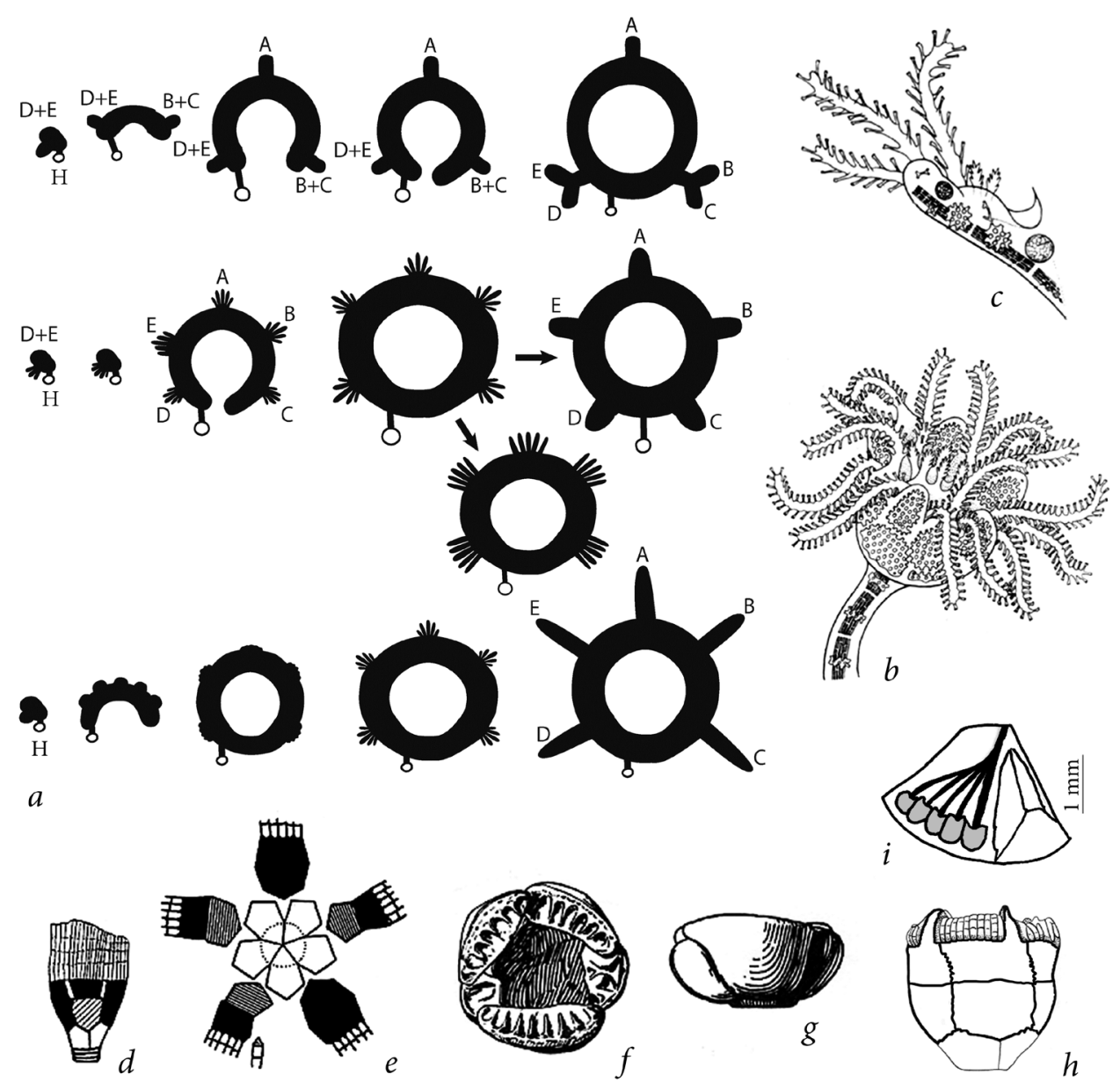

Figure 4. Hypothetical transformations of ambulacral system ontogenesis leading to true pentaradiality in crinoids, diagrammatically: (a) upper row: successive stages in ontogenesis of the 2-1-2 type ambulacral system in the crinoid ancestors; middle row: hypothetical stages of the ambulacral system ontogenesis in Paleozoic crinoids, deduced from the morphology of some paedomorphic multiarmed disparids; bottom row: ontogenesis of the ambulacral system in present-day crinoids; (b) the "Pentacrinus" stage in ontogenesis of Antedon rosacea and (c) an arm primordium with five tentacle primoridia at that stage [49]; (d-g) Paleozoic paedomorphic multiarmed crinoids Anamesocrinus (d-e), Devonian of USA [50] and Allocatillocrinus rotundus (f-g) Pennsylvanian of USA [51]; multiarmed crinoid (?) Acolocrinus (h-i): (h) lateral view, Middle Ordovician of USA [52], (i) radial plate (oral view) with facets for arm attachment, documenting the origin of multiple arms via branching of radial channels, Estonia, Middle Ordovician, PIN4125/890.

To understand the origin of a closed ambulacral ring with three outbound radial ambulacra one needs to consider the morphology of all echinoderms, including carpozoans, which have been described by many previous researchers as originally having lacked radial symmetry $[4,8]$.

The idea of Sumrall \& Wray [13] that carpozoan echinoderms with one or two ambulacra evolved from pentaradial forms via paedomorphosis does not seem convincing because of the uniqueness of their structure, lack of variation in the number of ambulacra, and absence of intermediate forms. In any case, if one considers these echinoderms as deeply paedomorphic, it is necessary to hypothesize an ambulacral ring structure (closed or open) matching such reduced number of ambulacra and reconstruct the process of elevation (migration of the mouth from the anterior to the posterior body end, which occurred in all pentaradial echinoderms) in such forms.

It appears highly unlikely that the carpozoan hydrocoel was a closed ring and that their mouth migrated from the anterior to the posterior body end. The stable number of ambulacra in each carpozoan clade, never varying even in the form of rare aberrations, speaks against the presence of a closed ambulacral ring. Additionally, the absence among these clades of characteristically bent aberrant forms, such as occur among eocrinoids and crinoids $[19,30]$, suggests that the ontogenesis in these clades lacked the process of elevation (Figure 5). 

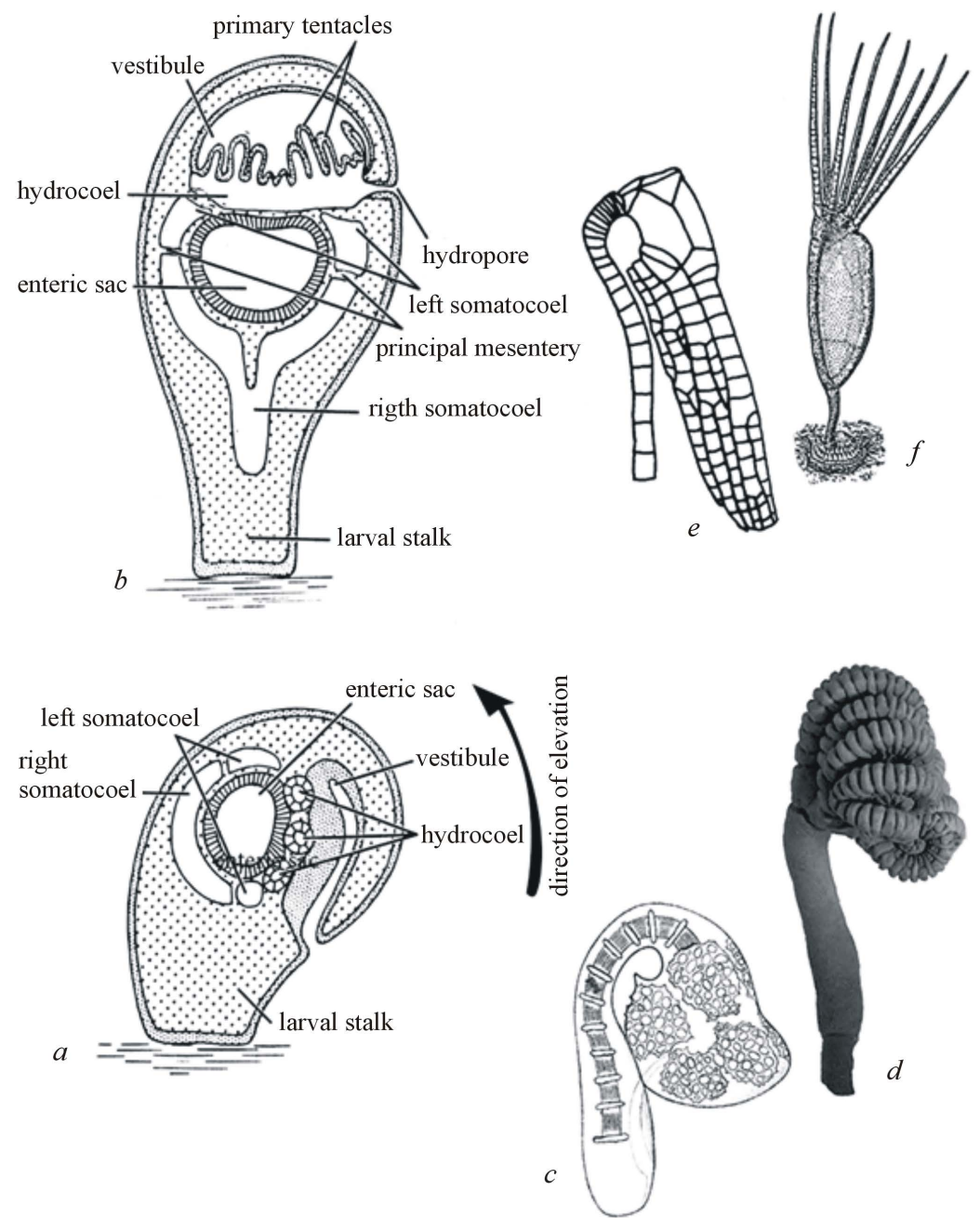

Figure 5. The process of elevation in crinoids (a-b) and aberrant forms of crinoids and eocrinoids (c-f): (a) larval morphology at an early stage of elevation; (b) same, at the end of elevation; (c) a late stage in the aberrant ontogenesis of the crinoid Antedon [53], (d) the recent cyrtocrinoid Gymnocrinus recheri, (e) the disparid crinoid Halisiocrinus (Ordovician), and (f) a reconstruction of the eocrinoid Rhipidocystis (Ordovician).

Nevertheless, whatever the view on the phylogeny of these forms, it is of no principal importance for the study of the origin of pentaradiality because paedomorphic changes repeat, only in the reverse order, the successive appearance of structures during phylogenesis. Therefore, we should focus on those traits of morphology and symmetry that are shared in common between carpozoans and radial echinoderms. From the standpoint of promorphology, the most important similarity in the designs of the two groups are the extensive and profound manifestations of metamerism (serial repetition) and asymmetry. In the following part we shall discuss these in more detail.

\section{METAMERISM}

The metamerism of adult echinoderms is profound and can be observed in various organs and body parts. The ambulacra and interambulacra of echinoids, stems and arms of crinoids, stems and brachioles of many blastozoans, stems and arms of asteroids and ophiuroids, and ambulacra of holothurians are all metameric. But the most characteristic of echinoderms is the original deep tripartite metamerism expressed in a linear arrangement along the anteroposterior body axis of the three pairs of coeloms in their embryos and larvae. This arrangement, sometimes referred to as archimery, is also typical of many bilaterians, including their adult stages. The origin of archimery and the gene system controlling its development can be related to the functional division of the bodies of first bilaterians into the anterior, middle, and posterior parts. The ontogenesis of these regions was controlled by colinear expression of a cluster of regula- 
tory genes. It is possible that this mechanism played a key role in the origin of first the triradial and then pentaradial symmetry of echinoderms.

Development of bilateral symmetry required individualization of the anterior body end, which determined the anteroposterior axis, and the upper and bottom sides, which determined the dorsoventral axis. These two axes together mark the sagittal plane, which allows distinguishing between the right and left body sides. In bilateral organisms the anteroposterior body axis is easy to identify based on the locations of the mouth and anus. In radially symmetric echinoderms it is more difficult because of the spiral shape of the gut. The problem can be solved by determining the order of activation of Hox genes. During ontogenesis of vertebrates, tunicates, and cephalochordates a cluster of 13 Hox genes is expressed colinearly along the anteroposterior body axis. Colinearity means that the order of activation of these genes is the same as their linear order within the cluster: the closer the gene's position to the 3' end of the cluster, the earlier the timing of its activation and the closer its expression domain to the anterior body end. Therefore, the anteroposterior axis can be identified from the succession of Hox genes expression domains. Peterson et al. [31] have applied this approach to echinoderms. Based on the fact that in larvae of the sea urchin, Strongylocentrotus purpuratus, the most posterior gene of the cluster, Hox 11/ $13 \mathrm{~b}$, which serves as a marker of the posterior homology across deuterostomes, is expressed in the paired somatocoels of the rudiment from which the adult body develops, they postulated that the anteroposterior body axis runs from the mouth to the posterior coeloms. This corresponds to the traditional oral-aboral axis [21]. Unlike in hemichordates, in which the coeloms are arranged in pairs on both sides of the body, the coeloms of adult echinoderms form a stack: the derivatives of the left hydrocoel are stacked on top of the left somatocoelar derivatives, which, in turn, are stacked on top of the right somatocoelar derivatives. In adult echinoderms the anteroposterior body axis runs through this stack [31,32]. In some echinoderms these axes are differently oriented in the adults and bilateral larvae, forming the angle of al- most $180^{\circ}$ in crinoids and $90^{\circ}$ in echinoids and asteroids.

Another important, and unique, aspect of Hox genes expression in echinoderms has been discovered in the same model species of sea urchins, S. purpuratus. In this species the order of activation of the most anterior genes in the cluster is reversed with respect to other bilaterian types (Figure 6): the group of three genes, Hox1, Hox2, and Hox3, has been translocated to the 5' end of the cluster and inverted [33].

Such rearranged Hox genes order has not been found in other echinoderm classes, but Mooi \& David [34] suggest that it will eventually be found in representatives of all echinoderm classes because, according to these authors, this genetic disorder is not an accident, but a special mechanism to build an adult symmetry completely different from the larval symmetry.

However, I think that the inversion of the three anteriormost Hox genes and their translocation to the 5' end of the cluster will not necessarily be discovered in all classes of present-day echinoderms because this rearrangement is a consequence rather than cause of the symmetry change that has occurred in the echinoderm evolution. Indeed, for all the radially symmetric echinoderms after their evolutionary transition to sedentary life style it was a physiological necessity that, after the larva attaches to the substratum with its preoral lobe, its mouth migrates from the anterior to the posterior body end. In the ontogenesis of present-day crinoids this is accomplished via a gradual elevation process, which leads to the "straightening" of the anteroposterior body axis and reorientation of the prospective mouth (Figure 5). In crinoids elevation takes place at relatively late stages of metamorphosis and appears to be controlled not directly by Hox genes, but by some downstream stages of the hierarchical regulatory cascade. As a consequence, among crinoids occur aberrant, curved forms resulting from unfinished elevation. Such aberrations can provide basis for the origin of taxa of a relatively high taxonomic rank, such for example as Paleozoic calceocrinaceans and Meso-Ceno-zoic spoon-like cyrtocrinids [19,30]. In the indirect ontogenesis of echinoids this stage is significantly modified compared to crinoids. The adult

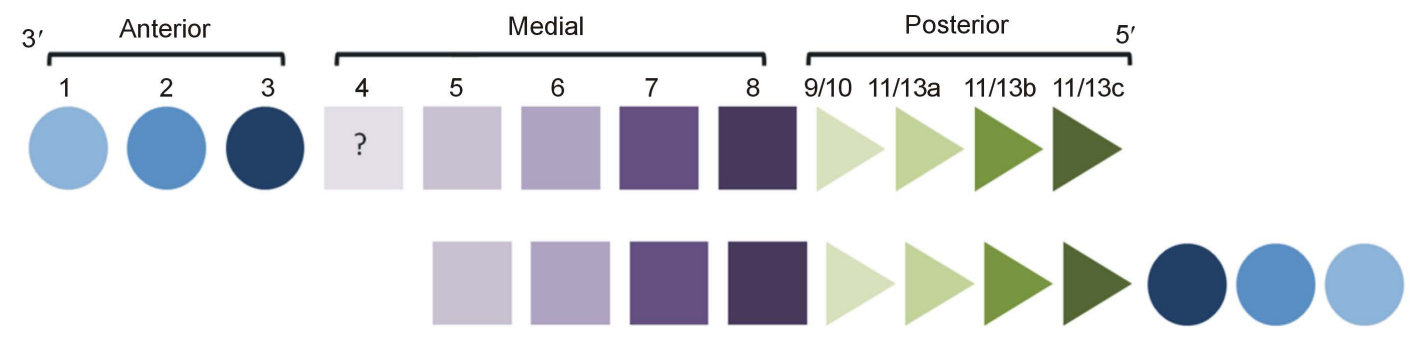

Figure 6. Hox genes spatial and temporal colinearity in echinoderms [33,34]. Upper row: the traditional gene order from the 3' to 5' end along the chromosome. Bottom row: the modified order, with the anterior group of genes translocated to the 5 ' end and inverted. 
organism develops from a rudiment on the left side of the larval body. This means that the initial and terminal stages of the elevation process have been shifted close to each other and incorporated into the early development of that rudiment, controlled directly by the anterior Hox genes. Apparently, this became possible due to a change in the spatial and temporal colinearity of the anterior Hox genes via their inversion and translocation within the cluster.

Therefore, the dramatic difference between the bilateral symmetry of larvae and the pentaradial symmetry of adults does not imply an abrupt transition from bilateral metameric to pentaradial forms during echinoderm evolution. There must be some intermediate stages between the two symmetry types. Such continuity can be seen in deviations from bilaterality and development of asymmetry.

\section{ASYMMETRY}

The rich manifestations of symmetry in echinoderms are accompanied by profound asymmetry [2,3]. In adults the latter is expressed, first of all, in their gut being coiled clockwise (Figure 2). In larvae the asymmetry is dramatically manifested in the unequal development of the left and right coeloms. This asymmetry of coeloms during larval development has parallels in the morphology of ancient carpozoan echinoderms.

In fact, in most carpozoans the body was bilaterallyasymmetric. The origin and phylogenetic relationships of Carpozoa remain subjects of debate. In my opinion, these animals have not been direct ancestors of radially symmetric echinoderms, but nevertheless their morphology reflects some important stages in the evolution of echinoderm radial symmetry. According to the opposite view, Carpozoa have evolved from pentaradial echinoderms via paedomorphosis. This hypothesis is in contradiction with a number of facts. I do not share this point of view, but I will not argue against it here because the issue is not of primary importance for the main subject of this article: paedomorphic changes also reflect, although in the reverse order, stages in the morphological evolution of a group.

Asymmetry is just as fundamentally characteristic of echinoderms as their pentaradial symmetry. The evolution of the asymmetric structure of echinoderms via reduction of their right anterior and middle coeloms is usually considered a consequence of their remote bilaterally symmetric ancestor having lain down onto the sea bottom on its lateral side. Some authors, for example Jefferies [5] think that that ancestor had lain down on its right side, while others, for example Holland [35] believe it was the left side. The new orientation has led to the reduction of the anterior and middle right coeloms with their associated structures and migration of the posterior right coelom to the left side. According to these authors, this resulted in the characteristic stacked arrangement of the coeloms. They assume that later in evolution the echinoderms returned to their original orientation, ventral side down, and attached themselves to the sea floor with the preoral lobe. The sedentary life style has resulted in development of radial symmetry, typical of many sedentary filtrators. The particular kind of symmetry, pentaradiality, became fixed probably because it turned out the most beneficial. Such are, in brief, the classical views on the evolution of echinoderm pentaradial symmetry. They offer a merely formal, too mechanistic explanation of the origin of echinoderm asymmetry and no explanation of why it was specifically pentaradiality that had to eventually evolve. Therefore, we will approach the evolution of echinoderm asymmetry and pentaradiality from a different angle.

The asymmetric development of the coeloms is the only available evidence that at one time echinoderms were oriented lateral side down. But there are a few Cambrian echinoderms with perfect bilateral symmetry of the body. Ctenoimbricata is one of them. It has a fully bilaterian body plan as adults and can be discerned as a bilateral ancestor of echinoderms [36]. But also possible that perfect bilateral symmetry of this genus is a more late adaptation because Ctenoimbricata enter in the geological record noticeably later (Cambrian Series 3, Stage 5) than bilateral-asymmetric and radial echinoderms [14, 36]. Therefore, it is actually possible that the ancestors of Echinodermata have never been perfectly bilaterally symmetric. Perhaps some asymmetry between their left and right body sides existed ever since they first became bilaterally symmetric. I believe it was further development of this original asymmetry that has led to the origin of bilaterally-asymmetric carpozoan echinoderms as well as (through developing asymmetry to its ultimate degree by bending the linear metamerism and closing it into radiality) radially symmetric echinoderms [15].

In the evolution of echinoderms, asymmetry may have been present ever since their ancestors acquired first morphological and morphogenetic traits of bilaterian organization (Figure 7). In fact, departures from bilateral symmetry must have occurred ever since it first evolved. While a perfectly bilateral body enables locomotion along a straight line and facilitates navigation towards a target, a bilaterally asymmetric body may have its own advantages in spite of less sophisticated control of locomotion: the animal moves in a spiral path without risk of accidentally losing the favorable environment. Such advantageous departures from bilaterality may have become fixed in the genome by natural selection. Therefore, it is possible that during the evolution of early Bilateria, including the echinoderm ancestors, both bilaterally 


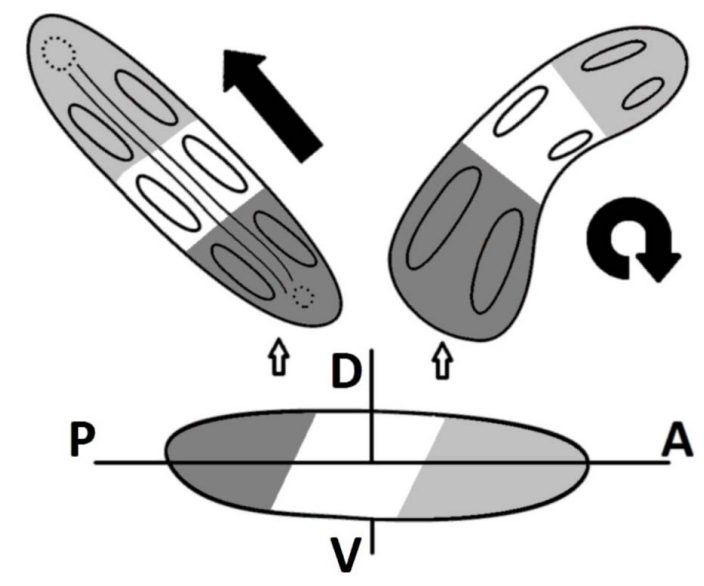

Figure 7. The origin of asymmetry in the early evolution of Bilateria via spontaneous deviations from bilateral symmetry, diagrammatically.

symmetric and bilaterally asymmetric forms evolved side by side.

If asymmetry is adaptive it can increase in evolution until it reaches its logical end point. This is the condition when a paired structure completely disappears on one side, due to either reduction or migration onto the opposite body side, while the analogous structure on the opposite side grows larger. The latter process culminates when the remaining structure circles around the body axis and eventually forms a closed ring or sphere.

Normally, all echinoderms are sinistral animals because their right coeloms either become reduced or migrate to the left body side.

Elucidating specific reasons why that particular type of asymmetry became fixed in echinoderm evolution requires special study.

In the majority of better studied animal and plant taxa displaying fixed directed asymmetry it was found to have been preceded by a randomly oriented asymmetric phenotype [37]. It is possible that sinistrality became fixed already in the soft-bodied ancestors of echinoderms. This is evidenced by the extreme rarity of situs inversus cases in adult echinoderms [9,38,39], although such larvae of present-day species have often been generated in a laboratory [29].

\section{RECONSTRUCTION OF THE HYDROCOEL STRUCTURE IN FOSSIL ECHINODERMS}

In adults of all present-day echinoderms the hydrocoel forms a closed ambulacral ring with several outbound radial channels. During ontogenesis the circular ambulacral channel develops from a pouchlike primordium. Therefore, it is likely that historically it evolved also from a pouchlike ancestral hydrocoel. This process must have included several hypothetical stages: from a simple am- bulacral pouch with a single arm to a horseshoe-shaped channel encircling the oesophagus and, finally, to a completely closed ambulacral ring with five radial outbound channels. I believe that these stages are reflected in the morphology of early Paleozoic echinoderms (Figure 8). In my opinion, the fossil echinoderm group that displays the ancestral hydrocoel with a single ambulacral channel are solutes. This hypothesis is not contradicted by the discovery of the oldest representative of solutes with a small attachment structure at the apex of its stele [40]. Many experts took it as evidence that it was a one-armed pelmatozoan echinoderm, the ancestor or, vice versa, a paedomorphic descendant of eocrinoids [10,13]. In my opinion, however, the attachment organ of those echinoderms is more likely to be homologous to the posterior part of the tail of hemichordates, some of which use it for temporary attachment, and clearly is not homologous to the attachment disk of present-day crinoid larvae because otherwise we would find traces of elevation at least among aberrant or juvenile solutes.

Moreover, it is unlikely that those animals had a closed ambulacral ring because otherwise we would find among solutes forms with several arms. Incidentally, it is an argument against both the hypothesis that solutes evolved from pentaradial echinoderms via paedomorphosis and hypothesis that they are primitive eocrinoids. A comparison of solutes and one-armed crinoids also suggests that solutes originally lacked pentamery. Whatever the degree of arms reduction in a crinoid, the ambulacral channel remains circular and is never reduced to a pouch within the single arm. This is indicated by retention of radial arrangement of the calyx plates and by the single arm being located not in the radius where the growth of the hydrocoel begins.

Cinctans had two ambulacra, the right one considerably shorter than the left. I suggest that in this case the ambulacral pouch became enlarged and elongated, and it was located on the ventral side under the mouth. The cinctan gut was curved, as is seen from the anus being located anteriorly, to the left of the mouth. This indicates that the hydrocoel expansion, increase in the number of ambulacra and increase of asymmetry were all correlated.

The existence of correlation between these processes is also confirmed by the structure of helicoplacoids, interpreted as triradiate echinoderms. Their derivation from pentaradial edrioasteroids via reduction of two ambulacra [41] appears unlikely. These Early Cambrian animals are among the most ancient echinoderms and apparently they display the original echinoderm triradiate symmetry. The ambulacral pouch with three ambulacra must have had the shape of a horseshoe with closely approximated ends or, possibly, a closed ring. This may be the reason why the first three ambulacra in the original pentaradial 


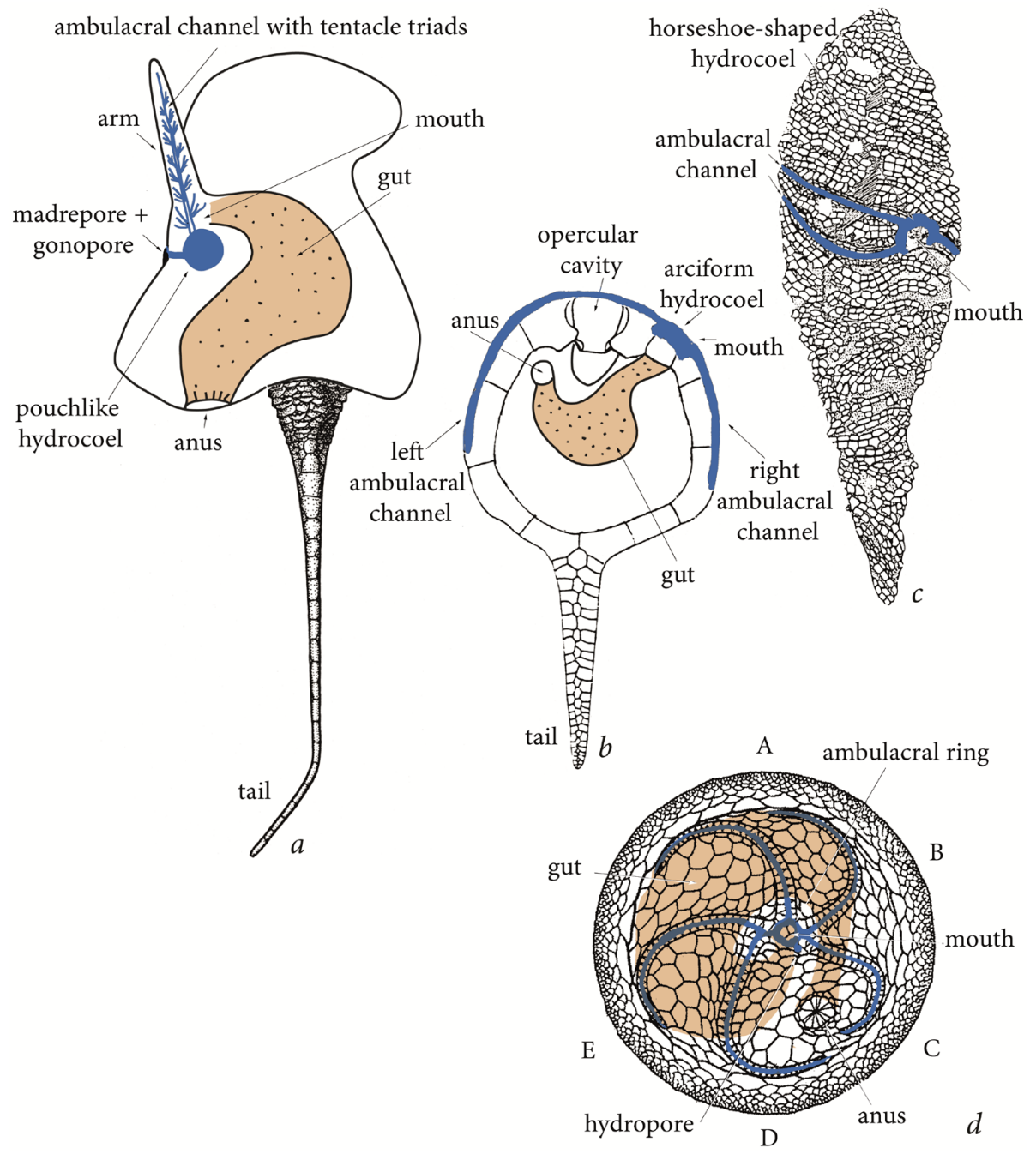

Figure 8. Morphology of bilaterally-asymmetric echinoderms and echinoderms with primary radial symmetry: (a) the solute Maennilia, (b) the cinctan Trochocystites, (c) the helicoplacoid Helicoplacus, and (d) edrioasteroid Isorophus.

2-1-2 pattern are generated by a mechanism (gradual growth) different from the mechanism generating the other two ambulacra (branching of already existing ambulacra).

The hydrocoel with five ambulacral channels transforms into a closed ambulacral ring, as is seen in all presentday echinoderms. Moreover, the ring remains closed if the number of radial channels increases or decreases. Nevertheless, it is possible that the ambulacral channel became a closed ring only with the origin of true pentamery, i.e. with all five channels coming directly off the ring. At the 2-1-2 stage of pentamery the channel could have been incompletely closed, with its two ends closely approximated. In particular, it is possible that the ambulacral channel of some edrioasteroids was unclosed.

This is suggested by several morphological characteristics of that group: the peristome often arched away from the interradius $\mathrm{CD}$, the hydropore shifted from the center towards the radius $\mathrm{C}$, and the ambulacra of some forms symmetrically curved. It is possible that in some blastozoan echinoderms (eocrinoids, rhombiferans, paracrinoids, and other groups) the circular channel was also unclosed. Perhaps it was this characteristic that made possible the existence among these groups of representatives with a strongly flattened theca and a highly variable arrangement of the ambulacra.

\section{CONCLUSIONS}

The origin of the initial tripartite metamerism typical of echinoderm larvae was predetermined already by the functional division of the bodies of early bilaterians: the head, trunk, and tail regions always have different functions. The development of these regions is controlled by colinear expression of a set of regulatory genes arranged successively on one chromosome. This ancestral tripar- 
tite metamerism and the gene system controlling its development must have played a role in the acquisition of the triradial first and then pentaradial symmetry by the circularly closed left middle coelom. The transformation of bilaterally-asymmetric three-segmented forms into pentaradial echinoderms correlated with profound changes in their morphology and life style. The main trend during this process was the increase of asymmetry. In the hydrocoel structure asymmetry reached its ultimate development when, as a result of clockwise growth around the oesophagus, the hydrocoel closed into a three-segmented ambulacral ring with three outbound radial hollow ambulacral tentacles. Branching of two of the latter shortly after leaving the ambulacral ring resulted in the origin of pentaradial symmetry of the 2-1-2 type, which quickly spread onto the arrangement of thecal plates. These profound changes in the morphology and symmetry took place within a short, by geological standards, period of time between the Late Vendian, when, in my opinion, first bilaterians started developing body appendages [42, 43], and the beginning of the Early Cambrian until the Atdabanian stage, when the first skeletal remains of echinoderms enter the geological record [44]. Molecular phylogenetic studies have suggested a different timing of the deuterostome body plans divergence $[45,46]$, but a discussion of that discrepancy is beyond the scope of this paper. The transformation of the 2-1-2 pattern into true pentaradiality, with the five tentacles coming directly off the ambulacral ring, has resulted from shifting the timing of tentacle branching onto earlier stages of ontogenesis and spreading the five primordia evenly over the ambulacral ring circumference. This occurred during the Ordovician.

Therefore, the evolution of radial symmetry in the food-gathering system and, eventually, the entire body of echinoderms was but a natural consequence of further development of their original asymmetry. Elucidation of the mechanisms involved in this process is an interesting subject for evolutionary developmental biology.

\section{ACKNOWLEDGEMENTS}

I am grateful to R. Rakitov for his linguistic assistance in preparation of this manuscript. The study was partially supported by grants from the Russian Foundation for Fundamental Research.

\section{REFERENCES}

[1] Beklemishev, V.N. (1964) Fundamentals of comparative anatomy of invertebrate animals. V. 1: Promorphologia. Nauka, Moscow, 432 p. [in Russian]

[2] MacBride, E.W. (1914) Text-book of embryology. Vol. I: Invertebrates, Macmillan, London.

[3] Grobben, K. (1923) Theoretische Erörterungen betreffend die phylogenetische Ableitung der Echinodermen. Sitzungsber. Akad. Wiss. Wien, 1.Abt, 132, 263-290.

[4] Smith, A.B. (2005) The pre-radial history of echinoderms. Geological Journal, 40, 255-280. http://dx.doi.org/10.1002/gj.1018

[5] Jefferies, R.P.S. (1986) The ancestry of the vertebrates. British Museum (Natural History), London, 376 p.

[6] Smith, A.B. (2008) Deuterostomes in a twist: The origins of a radical new body plan. Evolution and Development, 10, 493-503. http://dx.doi.org/10.1111/j.1525-142X.2008.00260.x

[7] Smith, A.B., Peterson K.J., Wray, G. and Littlewood, D.T.J. (2004) From bilateral symmetry to pentaradiality: The phylogeny of hemichordates and echinoderms. In: Cracraft, J. and Donoghue, M.J., Eds., Assembling the Tree of Life, 365-383.

[8] Jefferies, R.P.S. (1997) A defence of the calcichordates. Lethaia, 30, 1-10. http://dx.doi.org/10.1111/j.1502-3931.1997.tb00437.x

[9] Ubaghs, G. (1967) Stylophora. Treatise on Invertebrate Paleontology. Part S. Echinodermata 1 (2): S495-S565. Geological Society of America and the University of Kansas Press.

[10] Parsley, R.L. (1997) The echinoderm classes stylophora and Homoiostelea: Non Calciochordata. In: Waters, J.A. and Maples, C.G., Eds., Geobiology of Echinoderms, Paleontological Society Papers, 3, 225-248.

[11] David, B., Lefebvre, B., Mooi, R. and Parsley, R.L. (2000) Are homalozoans echinoderms? An answer from the extraxial-axial theory. Paleobiology, 26, 529-555. http://dx.doi.org/10.1666/0094-8373(2000)026<0529:AH $\mathrm{EAAF}>2.0 . \mathrm{CO} ; 2$

[12] Lefebvre, B. (2000) Homologies in Stylophora: A test of the "calcichordate theory". Geobios, 33, 359-364. http://dx.doi.org/10.1016/S0016-6995(00)80163-1

[13] Sumrall, C.D. and Wray, G.A. (2007) Ontogeny in the fossil record: Diversification of body plans and the evolution of "aberrant" symmetry in Paleozoic echinoderms. Paleobiology, 33, 149-163. http://dx.doi.org/10.1666/06053.1

[14] Smith, A.B., Zamora, S. and Alvaro, J. (2013) The oldest echinoderm faunas from Gondwana show echinoderm body plan diversification was rapid. Natural Community, 4, 1385. http://dx.doi.org/10.1038/ncomms2391

[15] Rozhnov, S.V. (2012) Development of symmetry and asymmetry in the early evolution of the echinoderms. Paleontological Journal, 46, 780-792. http://dx.doi.org/10.1134/S0031030112080114

[16] Rozhnov, S.V. and Jefferies, R.P.S. (1996) A new stemchordate solute from the Middle Ordovician of Estonia. Geobios, 29, 91-109.

http://dx.doi.org/10.1016/S0016-6995(96)80074-X

[17] Rozhnov, S.V. (2012) The anteroposterior axis in echinoderms and displacement of the mouth in their phylogeny and ontogeny. Biology Bulletin, 39, 162-171. http://dx.doi.org/10.1134/S1062359012020094

[18] Sprinkle, J. (1973) Morphology and evolution of blastozoan echinoderms. Harvard University Museum of Com- 
parative Zoology, Cambridge, Special Publication, 1-283.

[19] Rozhnov, S.V. (2002) Morphogenesis and evolution of crinoids and other pelmatozoan echinoderms in the Early Paleozoic. Paleontological Journal, 36, S525-S674.

[20] Hotchkiss, F.H.C. (1998) A “ray-as-appendages” model for the origin of pentamerism in echinoderms. Paleobiology, 24, 200-214.

[21] Minsuk, S.B., Turner, F.R., Andrews, M.E. and Raff, R.A. (2009) Axial patterning of the pentaradial adult echinoderm body plan. Development Genes and Evolution, 219, 89-101.

[22] Sumrall, C.D. and Sprinkle, J. (1998) Phylogenetic analysis of living Echinodermata based on primitive fossil taxa. In: Mooi, R. and Telford, M., Eds., Echinoderms: San Francisco, A.A. Balkema, Rotterdam/Brookfield, 81-87.

[23] Bell, B.M. (1975) Ontogeny and systematics of Timeischytes castery, n, sp.: An enigmatic Devonian edrioasteroids. Bulletins of American Paleontology, 67, 33-56.

[24] Bell, B.M. (1976) Phylogenetic implications of ontogenetic development in the class Edrioasteroidea (Echinodermata). Journal of Paleontology, 50, 1001-1019.

[25] Sumrall, C.D. and Sprinkle, J. (1999) Early ontogeny of the glyptocystitid rhombiferan Lepadocystis moorei. In: Carnevali, M.D.C. and Bonasoro, F., Eds., Echinoderm Research, A.A. Balkema, Rotterdam, 409-414.

[26] Sumrall, C.D. and Shumacher, G.A. (2002) Cheirocystis fultonensis, a new glyptocystitoid rhombiferan from the Upper Ordovician of the Cincinnati Arch-comment on cheirocrinid ontogeny. Journal of Paleontology, 76, 843851.

http://dx.doi.org/10.1666/0022-3360(2002)076<0843:CF ANGR $>2.0 . \mathrm{CO} ; 2$

[27] Broadhead, T.W. and Sumrall, C.D. (2003) Heterochrony and paedomorphic morphology of Sprinkleocystis ektopios, new genus and species (Rhombifera, Glyptocystida) from the middle Ordovician (Caradoc) of Tennessee. Journal of Paleontology, 77, 113-120. http://dx.doi.org/10.1666/0022-3360(2003)077<0113:HA $\underline{\text { PMOS }>2.0 . C O ; 2}$

[28] Parsley, R.L. and Zhao, Y. (2006) Long stalked eocrinoids in the basal Middle Cambrian Kaili Biota, Taijaing County Guizhou Province, China. Journal of Paleontology, 80, 1058-1071.

[29] Ivanova-Kasas, O.I. (1978) Comparative embryology of invertebrate animals: Echinoderms and hemichordates. Nauka, Moscow, 163 p. [in Russian]

[30] Rozhnov, S.V. (1998b) Crookedness of the stem and crown of pelmatozoan echinoderms as resulting from different kinds of heterochrony. In: Carnevali, M.D.C. and Bonasoro, F., Eds., Echinoderm Research, A.A. Balkema, Rotterdam, 385-390.

[31] Peterson, K.J., Arenas-Mena, C. and Davidson, E.H. (2000) The A/P axis in echinoderm ontogeny and evolution: Evidence from fossils and molecules. Evolution and Development, 2, 93-101. http://dx.doi.org/10.1046/j.1525-142x.2000.00042.x

[32] David, B. and Mooi, R. (1998) Major events in the evolution of echinoderms viewed by the light of embryology.
In: Mooi, R. and Telford, M., Eds., Echinoderms: San Francisco, A.A. Balkema, Rotterdam/Brookfield, 21-28.

[33] Cameron, R.A., Rowen, L., Nesbitt, R., Bloom, S., Rast, J.P., et al. (2006) Unusual gene order and organization of the sea urchin Hox claster. Journal of Experimental Zoo$\log y(\mathrm{~B}), 306,45-47$. http://dx.doi.org/10.1002/jez.b.21070

[34] Mooi, R. and David, B. (2008) Radial symmetry, the anterior/posterior axis, and echinoderm Hox genes. Annual Review of Ecology, Evolution, Systematic, 39, 43-62.

[35] Holland, N.D. (1988) The meaning of developmental asymmetry for echinoderm evolution: A new interpretation. In: Paul, C.R.C. and Smith, A.B., Eds., Echinoderm Phylogeny and Evolutionary Biology, Clarendon Press, Oxford, 13-25.

[36] Zamora, S., Rahman, I.A. and Smith, A.B. (2012) Plated Cambrian bilaterians reveal the earliest stages of echinoderm evolution. PLOS ONE, 7, e38296. http://dx.doi.org/10.1371/journal.pone.0038296

[37] Levin, M. and Palmer, A.R. (2007) Left-right pattering from the inside out: Widespread evidence for intracellular control. BioEssays, 29, 271-287. http://dx.doi.org/10.1002/bies.20545

[38] Smith, A.B. and Arbizu, M.A. (1987) Inverse larval development in a Devonian edrioasteroid from Spain and the phylogeny of the Agelacrinitidae. Lethaia, 20, 49-62. http://dx.doi.org/10.1111/j.1502-3931.1987.tb00759.x

[39] Rozhnov, S.V. (1998) The left-right asymmetry in echinoderms. In: Mooi, R. and Telford, M., Eds., Echinoderms: San Francisco, A. A. Balkema, Rotterdam/Brookfield, 73-78.

[40] Daley, P.E.J. (1996) The first solute which is attached as an adult: A Mid-Cambrian fossil from Utah with echinoderm and chordate affinities. Zoological Journal of the Linnean Society, 117, 403-440. http://dx.doi.org/10.1111/j.1096-3642.1996.tb01659.x

[41] Sprinkle, J. and Wilbur, B. (2005) Deconstructing helicoplacoids: Reinterpreting the most enigmatic Cambrian Echinoderm. Geological Journal, 40, 281-293. http://dx.doi.org/10.1002/gj.1015

[42] Rozhnov, S.V. (2009) Development of the trophic structure of Vendian and Early Paleozoic marine communities. Paleontological Journal, 43, 1364-1377. http://dx.doi.org/10.1134/S0031030109110021

[43] Rozhnov, S.V. (2010) From Vendian to Cambrian: The beginning of morphological disparity of modern metazoan phyla. Russian Journal of Developmental Biology, 46, 357-368. http://dx.doi.org/10.1134/S1062360410060032

[44] Rozhnov, S.V., Fedorov, A.B. and Sayutina, T.A. (1992) Lower Cambrian echinoderms from the territory of the USSR. Paleontological Journal, 1, 53-66.

[45] Smith, A.B. (1999) Dating the origin of metazoan body plans. Evolution and Development, 1, 138-142. http://dx.doi.org/10.1046/j.1525-142x.1999.99027.x

[46] Swalla, B.J. and Smith, A.B. (2008) Deciphering deuterostome phylogeny: Molecular, morphological and palaeontological perspectives. Philosophical transactions of 
the Royal Society (B), 363, 1557-1568.

[47] Bury, H. (1888) The early stages in the development of Antedon rosacea. Philosophical Transactions of the Royal Society, London (B), 129, 257-301.

http://dx.doi.org/10.1098/rstb.1888.0010

[48] Chadwick, H.C. (1907) Antedon. Proceedings and Transactions of the Liverpool Biological Society, 21, 371-417.

[49] Thompson, W. (1865) On the embryology of Antedon rosaceus. Philosophical Transactions of the Royal Society, London, 155, 513-544.

[50] Moore, R.C. (1962) Ray structures of some inadunate crinoids. The Paleontological Institute, The University of
Kansas, Article 5, 1-47.

[51] Moore, R.C. (1940) New genera of Pennsilvanian crinoids from Kansas, Oklahoma and Texas. Bulletin of the Scientific Laboratories of Denison University, 35, 32-54.

[52] Kesling R.V. and Paul C.R.C. (1971) Agostocrinus and Acolocrinus, two new Ordovician crinoids with peculiar ray and respiratory structures. Contributions from the University of Michigan Museum of Paleontology, 23, 221-237.

[53] Barrois, J. (1888) Development de la comatule (C. mediterranea). Recueil Zoologique Suisse, 8, 477-484. 